\title{
Éditorial
}
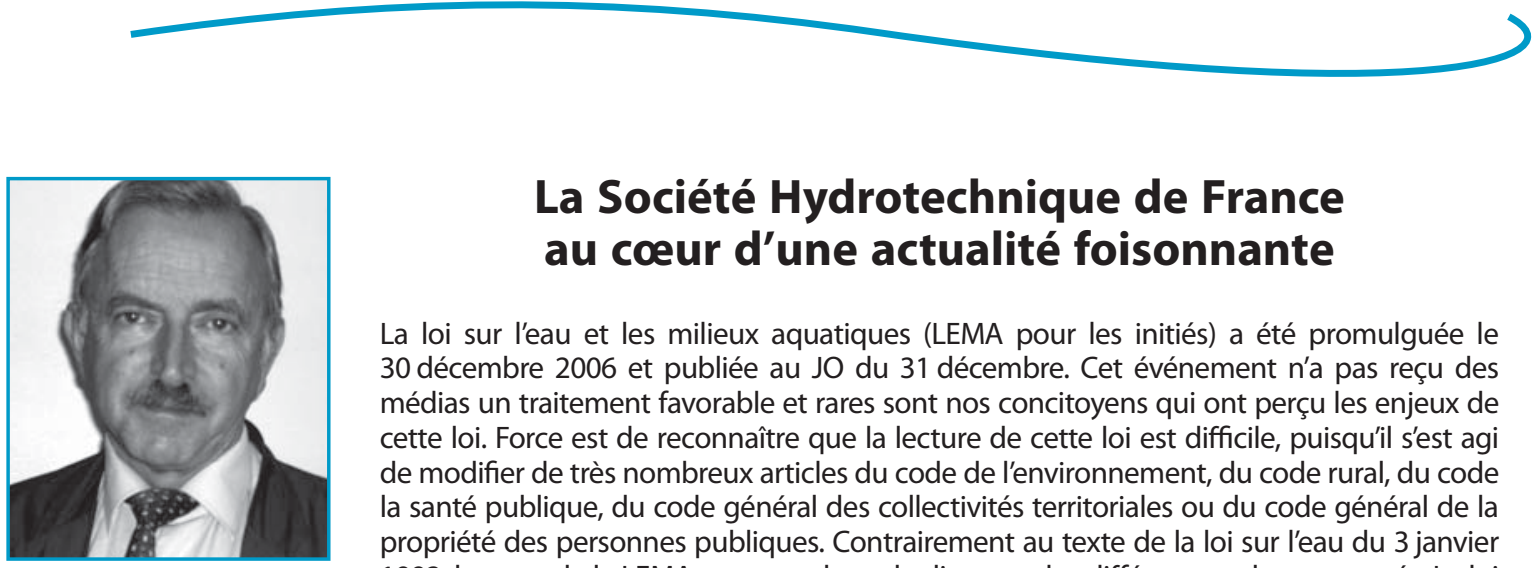

\section{La Société Hydrotechnique de France au cœur d'une actualité foisonnante}

La loi sur l'eau et les milieux aquatiques (LEMA pour les initiés) a été promulguée le 30 décembre 2006 et publiée au JO du 31 décembre. Cet événement n'a pas reçu des médias un traitement favorable et rares sont nos concitoyens qui ont perçu les enjeux de cette loi. Force est de reconnaître que la lecture de cette loi est difficile, puisqu'il s'est agi de modifier de très nombreux articles du code de l'environnement, du code rural, du code la santé publique, du code général des collectivités territoriales ou du code général de la propriété des personnes publiques. Contrairement au texte de la loi sur l'eau du 3 janvier 1992, le texte de la LEMA suppose donc de disposer des différents codes concernés. La loi porte d'abord sur la mise en cohérence avec les objectifs de la directive cadre européenne sur l'eau d'octobre 2000 (DCE), donc la préservation des milieux aquatiques ; mais de nombreux points méritent d'être cités :

- le droit d'accès à l'eau potable pour tous dans des conditions d'accès économiquement acceptables; dans le texte figurent explicitement des modifications au service de l'eau et de l'assainissement ;

- les eaux pluviales (collecte, transport, stockage, traitement) qui peuvent donner lieu à la constitution d'un service administratif relevant des communes, son financement pouvant être assuré par une taxe annuelle; les particuliers pourront bénéficier d'un crédit d'impôt pour les travaux de récupération ;

- la possibilité de modifier la régulation par déclaration d'utilité publique des ouvrages de retenue en période d'étiage des eaux;

- la sécurité des barrages et des ouvrages hydrauliques;

- la gestion des boues de station d'épuration, notamment leur épandage, et la mise en place d'un fonds de garantie ; - le renforcement du rôle des comités de bassin et la réforme des redevances des agences rendues conforme à la constitution.

La création de I'Office National de l'Eau et des Milieux Aquatiques (ONEMA) qui se substitue au Conseil Supérieur de la Pêche devrait déboucher sur un renforcement d'un établissement public focalisé sur la surveillance et de la connaissance de la qualité des eaux des rivières et des lacs, au bénéfice des services de l'Etat et des agences de l'eau, des SAGE et des SDAGE.

Cette analyse sommaire est loin d'être exhaustive, et la publication des décrets d'application prévue courant 2007 permettra à la SHF de revenir sur un texte de première importance dans le domaine de l'eau.

Un autre texte est attendu avec intérêt par la communauté de l'eau ; il s'agit du quatrième rapport du Groupe d'experts intergouvernemental sur l'évolution du climat (GIEC ou IPCC pour les anglophones). Le rapport de 2001 avait proposé une fourchette de l'ordre de 1 à 6 degrés pour le réchauffement moyen de notre planète d'ici 2100. Les trois rapports attendus en 2007 devraient permettre de préciser d'autres aspects du changement climatique (le niveau de la mer, la calotte glaciaire, les événements extrêmes) et surtout les impacts anthropiques ainsi que les mesures compensatoires à envisager. Le sujet est complexe et les prochains colloques organisés par la SHF, notamment celui des 27 et 28 mars à Lyon sur « Variations climatiques et hydrologie », devraient contribuer à l'appropriation collective de ces rapports et à leur prise en compte dans le contexte de l'Europe de l'Ouest.

Je souhaiterais maintenant revenir sur un concept que les organismes internationaux utilisent abondamment « Integrated Water Resources Management (IWRM) »; tous les principes sous-tendus par la gestion intégrée des ressources en eau sont évidemment pertinents qu'il s'agisse des solidarités spatiales (amont/aval) ou temporelles (saisonnières, interannuelles ou inter générations), de la prise en compte des externalités difficilement quantifiables ou d'objectiver les méthodes d'arbitrage entre les différents usages de l'eau. Le colloque des 11 et 12 juin sur la « Gestion active des eaux » devrait permettre d'éclairer la faisabilité d'une modulation inter annuelle de l'exploitation des aquifères. Le colloque intitulé "Gestion sociale et économique » prévu les 17 et 18 octobre prochain à Paris devrait apporter des éléments d'éclairage sur les pratiques susceptibles de dépasser le stade des concepts et des bonnes intentions. La gestion de la demande en eau doit être mise en regard de la disponibilité des ressources ; elle mérite une égale attention.

Je ne saurais terminer ce premier éditorial 2007 de la revue internationale de l'eau « La Houille Blanche » sans rendre un hommage particulier à mon prédécesseur, René Coulomb, pour son activité remarquable à la présidence de la SHF. René Coulomb rejoint Georges Maurin comme président d'honneur. La SHF a besoin de leur savoir faire pour poursuivre son développement en harmonie avec ses nombreux partenaires.

\section{Président de la Société Hydrotechnique de France}

